\title{
Do financial professionals behave according to prospect theory? An experimental study
}

\author{
Mohammed Abdellaoui • Han Bleichrodt • \\ Hilda Kammoun
}

Received: 20 September 2011 / Accepted: 24 September 2011 / Published online: 16 October 2011 (C) The Author(s) 2011. This article is published with open access at Springerlink.com

\begin{abstract}
Prospect theory is increasingly used to explain deviations from the traditional paradigm of rational agents. Empirical support for prospect theory comes mainly from laboratory experiments using student samples. It is obviously important to know whether and to what extent this support generalizes to more naturally occurring circumstances. This article explores this question and measures prospect theory for a sample of private bankers and fund managers. We obtained clear support for prospect theory. Our financial professionals behaved according to prospect theory and violated expected utility maximization. They were risk averse for gains and risk seeking for losses and their utility was concave for gains and (slightly) convex for losses. They were also averse to losses, but less so than commonly observed in laboratory studies and assumed in behavioral finance. A substantial minority focused on gains and largely ignored losses, behavior reminiscent of what caused the current financial crisis.
\end{abstract}

Keywords Prospect theory - Loss aversion - Field data - Behavioral finance . Experimental economics

\section{JEL Classification D81 - G11}

\section{Introduction}

A central question in experimental and behavioral economics is whether findings obtained in the lab can be replicated in more realistic settings. This study contributes

\footnotetext{
M. Abdellaoui · H. Kammoun

HEC, Paris, France

e-mail: abdellaoui@hec.fr

H. Bleichrodt $(\varangle)$

Erasmus University Rotterdam, Rotterdam, The Netherlands

e-mail: bleichrodt@ese.eur.nl
} 
to answering that question. We explore whether the findings on the psychology of money and risk under prospect theory (Kahneman and Tversky 1979; Tversky and Kahneman 1992), currently the most influential theory of decision under risk, can be extrapolated from students in the experimental lab to financial professionals in the field. There is abundant evidence about the capacity of prospect theory to account for discrepancies from rationality in the lab, and these observations can be used to explain many anomalies that are hard to reconcile with the traditional finance paradigm. ${ }^{1}$ However, scant empirical evidence exists regarding the psychology of risk of financial professionals. Do they also behave according to prospect theory? And, if so, can we use one common specification of prospect theory that is applicable to students in the lab and financial professionals alike or do we need different specifications of prospect theory, one for risky choices in the lab and another for financial professionals in the field?

There are several reasons why financial professionals might behave differently from students in the lab. While the latter generally face one-shot independent choices without any systematic feedback on uncertainty resolution, financial professionals are provided with such feedback, and are evaluated on the basis of their overall performance in a usual reference period. Moreover, financial professionals are trained to diversify risks and to evaluate the contribution of an asset to their overall portfolio. Several studies suggest that trading experience and opportunities for learning tend to mitigate deviations from rationality (Myagkov and Plott 1997; List 2003; van de Kuilen and Wakker 2006).

We measured prospect theory in a sample of financial professionals using a measurement method that was recently implemented in the lab (Abdellaoui et al. 2007b). Our professionals were private bankers and money managers handling \$300 million on average. Like us, Kliger and Levy (2009) and Gurevich et al. (2009) estimated prospect theory using data from real financial actors. They used data from European options based on the S\&P 500 index and US options written on the stocks of 30 companies leading the S\&P 100 index, respectively. Their parameter estimates were consistent with prospect theory although the degree of loss aversion was less pronounced than typically observed in student samples.

Our article complements the analyses of Kliger and Levy (2009) and Gurevich et al. (2009). Whereas they used real market data and were able to observe repeated decisions over a period of 5 years, our method avoids some of the drawbacks of theirs. First, we made no simplifying assumptions about prospect theory's parameters. Second, whereas their measurements only applied to aggregate data, we measured prospect theory for each professional separately and, consequently, we could account for preference heterogeneity, which was indeed clearly present in our data. Finally, both Kliger and Levy's (2009), Gurevich et al.'s (2009) and our estimations of loss aversion, probability weighting, and utility curvature depend crucially on the assumption that

\footnotetext{
1 Examples are the equity premium puzzle (Benartzi and Thaler 1995), the excess volatility and high predictability of stock returns (Barberis et al. 2001), the value premium (Barberis and Huang 2001), and the disposition effect (Barberis and Xiong 2009). Empirical studies confirming the predictions of prospect theory for financial decisions include Thaler et al. (1997); Gneezy and Potters (1997); Gneezy et al. (2003); Coval and Shumway (2005), and Haigh and List (2005).
} 
financial professionals behave according to prospect theory. We, therefore, included several tests of this assumption. Our aggregate results are largely in agreement with those of Kliger and Levy (2009) and Gurevich et al. (2009), despite differences in methodology, and provide confidence in the external validity of their and our results.

We observed clear support for prospect theory. Our financial professionals did indeed behave according to prospect theory and violated expected utility maximization systematically. They were risk averse for gains and risk seeking for losses, had concave utility for gains and convex utility for losses, and overall they were loss averse. However, their behavior deviated from the assumptions that are commonly made in modeling financial decision-making under prospect theory in two respects. First, our financial professionals were considerably less averse to losses than what is typically observed in laboratory studies using students, and what is assumed in behavioral finance. A sizeable proportion of the professionals were, in fact, not loss averse, but displayed an opposite type of behavior, gain seeking. They focused mainly on gains and downplayed the possibility of losses. Such behavior can be linked to the current financial crisis. It has been suggested that the current financial situation may have been caused by financial professionals ignoring the possibility of losses. ${ }^{2}$ The second deviation was a violation of reflection, the assumption that utility for gains and utility for losses have equal curvature. Utility for gains was significantly more curved than utility for losses. Note that reflection is not central to prospect theory, but is commonly assumed for convenience. Hence, the violations of reflection that we observed do not entail a violation of prospect theory.

This article is structured as follows. Section 2 reviews prospect theory. Section 3 reviews Abdellaoui et al.'s (2007b) measurement method. Section 4 describes the experimental method and stimuli used and Sect. 5 describes the results of our experiment. Section 6 discusses our findings and concludes the article.

\section{Prospect theory}

Let $(x, p ; y)$ denote the prospect that pays money amount $x$ with probability $p$ and money amount $y$ otherwise. In our measurements, we will only use such binary prospects involving at most two distinct money amounts. The decision maker's preference relation over prospects is denoted by $\succcurlyeq$. As usual, $\sim$ denotes indifference and $\succ$ denotes strict preference. The decision maker always prefers more money to less. A central assumption of prospect theory ${ }^{3}$ is that outcomes are evaluated as gains and losses relative to a reference point. Throughout the article, the reference point is denoted by 0 . Gains are money amounts larger than 0 and losses are money amounts smaller than 0. A gain prospect involves no losses and a loss prospect involves no gains. A mixed prospect involves both a gain and a loss. For gain [loss] prospects the notation $(x, p ; y)$ implicitly assumes that $x \geq[\leq] y$. For mixed prospects, it assumes that $x>0>y$.

\footnotetext{
2 For example, due to myopia or as a result of their remuneration scheme.

3 Because we only use binary prospects throughout this article, the original version of prospect theory (Kahneman and Tversky 1979) and the later version, cumulative prospect theory (Tversky and Kahneman 1992) are equivalent. We will, therefore, simply use the term prospect theory in what follows.
} 
Prospect theory's evaluation of prospects depends on the type of prospect under consideration. Mixed prospects are evaluated as

$$
w^{+}(p) U(x)+w^{-}(1-p) U(y),
$$

where $U$ is a utility function over money with $U(0)=0$. The utility function $U$ is a ratio scale, meaning that we can freely select the utility of one money amount. The functions $w^{+}$and $w^{-}$are probability weighting functions for gains and losses, respectively. The probability weighting functions are uniquely determined, are increasing in probability, and satisfy $w^{i}(0)=0$ and $w^{i}(1)=1, i=+,-$. Gain and loss prospects are evaluated as

$$
w^{i}(p) U(x)+\left(1-w^{i}(p)\right) U(y), i=+,-
$$

Tversky and Kahneman (1992) argued that utility is S-shaped, concave for gains and convex for losses, and that probability weighting is inverse S-shaped, overweighting small probabilities and underweighting moderate and large probabilities. Empirical evidence generally confirms these assumptions (e.g., Abdellaoui et al. (2007b) and Booij and Kuilen (2009) on utility and Gonzalez and Wu (1999), Abdellaoui (2000), and Bleichrodt and Pinto (2000) on probability weighting). The degree of concavity for gains is generally larger than the degree of convexity for losses. The exception is Tversky and Kahneman (1992) who found equal curvature for gains and losses and referred to this as reflection. Reflection is commonly assumed in applications of prospect theory with many studies imposing the additional restriction that utility for gains and losses is linear (e.g., Benartzi and Thaler 1995; Barberis et al. 2001). S-shaped utility and inverse S-shaped probability weighting jointly imply the fourfold pattern of risk attitudes: risk aversion for probable gains and unlikely losses, and risk seeking for unlikely gains and probable losses. ${ }^{4}$

A central assumption of prospect theory is loss aversion: people are more sensitive to losses than to absolutely commensurate gains. There is considerable qualitative support for loss aversion (e.g., Camerer et al. 1997; Tom et al. 2007) and it is the key factor in explaining people's attitudes toward risk (Rabin 2000).

However, the measurement of loss aversion is complex because it requires a complete elicitation of utility on the gain and loss domains simultaneously. The difficulty in completely measuring utility is that probability weighting for gains and for losses can be different. Until Abdellaoui et al. (2007b), ABP from now on, there was no method to measure prospect theory's utility function without introducing simplifying assumptions.

An additional complication in measuring loss aversion is that there is no consensus about the definition of loss aversion. ABP (2007b) compared the main definitions that have been proposed and concluded that the definitions of Kahneman and Tversky (1979) and Köbberling and Wakker (2005) were empirically the most useful. Kahneman and Tversky (1979) defined loss aversion as $-U(-x)>U(x)$ for all gains $x$

\footnotetext{
${ }^{4}$ Under prospect theory, concave [convex] utility and risk aversion [seeking] are not equivalent due to probability weighting and loss aversion.
} 
included in the domain, reflecting that losses loom larger than gains. A special case of this definition is the requirement that loss aversion holds when $-U(-1)>U(1)$. This definition follows when a power specification is used for utility, as in Tversky and Kahneman (1992) and also in Kliger and Levy (2009) and Gurevich et al. (2009). Köbberling and Wakker (2005) defined loss aversion as the kink at the reference point and suggested that the loss aversion coefficient should be defined as the ratio of the left over the right derivative of $U$ at the reference point. A similar definition was suggested by Benartzi and Thaler (1995).

The best known quantification of loss aversion is by Tversky and Kahneman (1992). They adopted a variant of the definition of Kahneman and Tversky (1979) and estimated that the coefficient of loss aversion was equal to 2.25. This value has been widely used in applications. Later studies that quantified loss aversion generally observed less aversion.

\section{Measurement method}

Table 1, taken from ABP (2007b), summarizes their method for measuring utility under prospect theory. The second column shows the quantity measured, the third shows the indifference elicited to measure this quantity, and the fourth shows the implication of this indifference under prospect theory. The final column shows the stimuli we used in our experiment reported in Sect. 4. We will briefly describe ABP's method. The reader is referred to ABP (2007b) for a more detailed description.

The method consists of four stages. In the first stage, probabilities $p_{\ell}$ and $p_{g}$ are determined for which $w^{-}\left(p_{\ell}\right)=w^{+}\left(p_{g}\right)=1 / 2$, i.e., loss and gain probabilities with decision weights $1 / 2$. Under expected utility, where there is no probability weighting, $p_{\ell}=p_{g}=1 / 2$. To determine $p_{\ell}$ and $p_{g}$, we first elicited losses $\mathcal{L}_{0}, \mathcal{L}_{1}$, and $\mathcal{L}_{2}$ and gains $\mathcal{G}_{0}, \mathcal{G}_{1}$, and $\mathcal{G}_{2}$ that were equally spaced in utility units: $U\left(\mathcal{L}_{0}\right)-U\left(\mathcal{L}_{1}\right)=U\left(\mathcal{L}_{1}\right)-U\left(\mathcal{L}_{2}\right)$ and $U\left(\mathcal{G}_{2}\right)-U\left(\mathcal{G}_{1}\right)=U\left(\mathcal{G}_{1}\right)-U\left(\mathcal{G}_{0}\right)$. As explained in Table 1, two indifferences were needed to elicit losses $\mathcal{L}_{0}, \mathcal{L}_{1}$, and $\mathcal{L}_{2}$ and two indifferences to elicit gains $\mathcal{G}_{0}, \mathcal{G}_{1}$, and $\mathcal{G}_{2}$. Then subjects were asked to state probabilities $p_{\ell}$ and $p_{g}$ such that $\mathcal{L}_{1} \sim\left(\mathcal{L}_{2}, p_{\ell} ; \mathcal{L}_{0}\right)$ and $\mathcal{G}_{1} \sim\left(\mathcal{G}_{2}, p_{g} ; \mathcal{G}_{0}\right)$. These equivalences imply that $w^{-}\left(p_{\ell}\right)=w^{+}\left(p_{g}\right)=1 / 2 .^{5}$

In the second stage, the probability $p_{\ell}$ was used to measure utility on the loss domain $\left[L_{1}, 0\right]$, where $L_{1}$ is the loss that has utility $-1 .^{6}$ This loss can be chosen arbitrarily because, as explained in Sect. 2 , the utility function $U$ is a ratio scale in prospect theory. The measurement of $U$ was performed through simple certainty equivalence questions. Two losses, $L_{A}$ and $L_{B}$ with known utility, were chosen and we asked for the loss $L_{r}$ that made the decision maker indifferent to a prospect paying $L_{A}$ with probability $p_{\ell}$ and $L_{B}$ with probability $1-p_{\ell}$, i.e., $\left(L_{A}, p_{\ell} ; L_{B}\right) \sim L_{r}{ }^{7}$ This implies

\footnotetext{
5 By Eq. 2, $\mathcal{L}_{1} \sim\left(\mathcal{L}_{2}, p_{\ell} ; \mathcal{L}_{0}\right)$ implies that $U\left(\mathcal{L}_{1}\right)=w^{-}\left(p_{\ell}\right) U\left(\mathcal{L}_{2}\right)+\left(1-w^{-}\left(p_{\ell}\right)\right) U\left(\mathcal{L}_{0}\right)$. Rearranging gives $\left(1-w^{-}\left(p_{\ell}\right)\right)\left(U\left(\mathcal{L}_{0}\right)-U\left(\mathcal{L}_{1}\right)\right)=w^{-}\left(p_{\ell}\right)\left(U\left(\mathcal{L}_{1}\right)-U\left(\mathcal{L}_{2}\right)\right)$. The equality $U\left(\mathcal{L}_{0}\right)-U\left(\mathcal{L}_{1}\right)=$ $U\left(\mathcal{L}_{1}\right)-U\left(\mathcal{L}_{2}\right)$ implies that $w^{-}\left(p_{\ell}\right)=1 / 2$. The conclusion that $w^{+}\left(p_{g}\right)=1 / 2$ is derived similarly.

6 Throughout we denote a loss with utility $-r$ as $L_{r}$ and a gain with utility $r$ as $G_{r}, r>0$.

${ }^{7}$ In the first question, we used $L_{1}$ and $L_{0}$ to determine $L_{0.5} . L_{1}, L_{0}$, and $L_{0.5}$ can then be used to determine $L_{0.75}$ and $L_{0.25}$, etc.
} 
Table 1 Measurement method ABP (2007b)

\begin{tabular}{|c|c|c|c|}
\hline Assessed quantity & Indifference & Under prospect theory & Choice variables \\
\hline \multicolumn{4}{|l|}{ Step 1} \\
\hline $\mathcal{L}_{1}$ & $\left(\mathcal{L}_{1}, p ; \mathcal{L}^{*}\right) \sim\left(\mathcal{L}_{0}, p ; \mathcal{L}\right)$ & $\begin{array}{l}U\left(\mathcal{L}_{0}\right)-U\left(\mathcal{L}_{1}\right)= \\
U\left(\mathcal{L}_{1}\right)-U\left(\mathcal{L}_{2}\right)\end{array}$ & $\begin{array}{l}p=0.33 \\
\mathcal{L}^{*}=-\$ 100\end{array}$ \\
\hline $\mathcal{L}_{2}$ & $\left(\mathcal{L}_{2}, p ; \mathcal{L}^{*}\right) \sim\left(\mathcal{L}_{1}, p ; \mathcal{L}\right)$ & & $\begin{array}{l}\mathcal{L}=-\$ 600 \\
\mathcal{L}_{0}=-\$ 1000\end{array}$ \\
\hline$p_{\ell}$ & $\mathcal{L}_{1} \sim\left(\mathcal{L}_{2}, p_{\ell} ; \mathcal{L}_{0}\right)$ & $w^{-}\left(p_{\ell}\right)=0.5$ & \\
\hline $\mathcal{G}_{1}$ & $\left(\mathcal{G}_{1}, p ; \mathcal{G}^{*}\right) \sim\left(\mathcal{G}_{0}, p ; \mathcal{G}\right)$ & $\begin{array}{c}U\left(\mathcal{G}_{2}\right)-U\left(\mathcal{G}_{1}\right)= \\
U\left(\mathcal{G}_{1}\right)-U\left(\mathcal{G}_{0}\right)\end{array}$ & $\begin{array}{l}p=0.33 \\
\mathcal{G}^{*}=\$ 100\end{array}$ \\
\hline $\mathcal{G}_{2}$ & $\left(\mathcal{G}_{2}, p ; \mathcal{G}^{*}\right) \sim\left(\mathcal{G}_{1}, p ; \mathcal{G}\right)$ & & $\begin{array}{l}\mathcal{G}=\$ 600 \\
\mathcal{G}_{0}=\$ 1000\end{array}$ \\
\hline$p_{g}$ & $\mathcal{G}_{1} \sim\left(\mathcal{G}_{2}, p_{g} ; \mathcal{G}_{0}\right)$ & $w^{+}\left(p_{g}\right)=0.5$ & \\
\hline \multicolumn{4}{|l|}{ Step 2} \\
\hline$L_{r} \in\left[L_{1}, 0\right]$ & $L_{r} \sim\left(L_{A}, p_{\ell} ; L_{B}\right)$ & $\begin{array}{l}U\left(L_{r}\right)=0.5 U\left(L_{A}\right) \\
\quad+0.5 U\left(L_{B}\right)\end{array}$ & $L_{1}=-\$ 100,000$ \\
\hline \multicolumn{4}{|l|}{ Step 3} \\
\hline$\ell$ & $L_{s} \sim(\ell, 0.5 ; 0)$ & $w^{-}(0.5) U(\ell)=-s$ & $s=0.25$ \\
\hline $\mathrm{g}$ & $0 \sim(g, 0.5 ; \ell)$ & $w^{+}(0.5) U(g)=s$ & \\
\hline$G_{s}$ & $G_{s} \sim(g, 0.5 ; 0)$ & $U\left(G_{s}\right)=w^{+}(0.5) U(g)=s$ & \\
\hline \multicolumn{4}{|l|}{ Step 4} \\
\hline$G_{r} \in\left[0, G_{s}\right]$ & $G_{r} \sim\left(G_{A}, p_{g} ; G_{B}\right)$ & $\begin{array}{l}U\left(G_{r}\right)=0.5 U\left(G_{A}\right) \\
\quad+0.5 U\left(G_{B}\right)\end{array}$ & \\
\hline
\end{tabular}

that $U\left(L_{r}\right)=w^{-}\left(p_{\ell}\right) U\left(L_{A}\right)+\left(1-w^{-}\left(p_{\ell}\right)\right) U\left(L_{B}\right)=1 / 2 U\left(L_{A}\right)+1 / 2 U\left(L_{B}\right)$. Consequently, $L_{r}$ is the midpoint of $L_{A}$ and $L_{B}$ in terms of utility.

The third stage provided a link between utility for losses and utility for gains. It started by selecting a loss $L_{s}$ with known utility $-s$ and then proceeded through three indifferences to find a gain $G_{s}$ such that $U\left(G_{s}\right)=-U\left(-L_{s}\right)=s$.

The fourth stage determined utility on the domain of gains $\left[0, G_{s}\right]$ through similar certainty equivalence questions as in stage 2 but now using the probability $p_{g}$.

\section{Experiment}

Subjects were 46 financial professionals (median age 40 years, nine female). The low number of female subjects was due to the scarcity of female financial professionals. It was difficult to find professionals willing to participate in the experiment. The sample was collected using a "snowball procedure" where participants recommended us to colleagues working in other institutions. Most subjects were private bankers, i.e., financial advisors responsible for managing clients' investment portfolios. Some were fund managers, i.e., portfolio managers in whose funds the private bankers invest. They were affiliated with multinational financial institutions based in Cleveland $\mathrm{OH}$, 
Boston MA, New York, Atlanta GA, Phoenix AZ, and Beirut, Lebanon. In total there were 24 professionals from the US and 22 professionals from Lebanon. They handled between $\$ 20$ million and $\$ 1$ billion with a median of $\$ 300$ million (mean $\$ 295$ million). None of the professionals were willing to disclose information about the performance of their portfolios, deeming it confidential company information.

The experiment was computer-run. To minimize response errors and to be sure that subjects understood the instructions, all interviews were conducted individually. They were conducted in the professionals' offices and took on average $30 \mathrm{~min}$.

In the introduction to the experiment, the professionals were told that the choices were designed to explore their attitudes toward risk, that their responses were confidential, and that there were no right or wrong answers and, therefore, no reason not to state their true answers. They were told that the choices represented investment opportunities and that the amounts represented the company's money. This wording was chosen to make the choices realistic and insure that the choices made reflected their preferences as professionals. This is different from most lab studies where choices are usually framed in terms of subjects' own money. We also informed the professionals that they would be shown their measured utility function at the end of the experiment. This provided strong motivation as they were curious about their results. We did not mention the concept of loss aversion, nor did we tell them how their attitude toward risk and their utility function would be measured.

Indifferences were elicited through a series of binary choices. We used a choicebased method because previous research has shown that choices lead to fewer inconsistencies than matching, where subjects are directly asked for their indifference values (Bostic et al. 1990). In the initial choice, the two prospects under consideration had equal expected value. The next choices then zeroed in on the professionals' indifference values either by making the chosen prospect less attractive or by making the prospect that was not chosen more attractive. Figure 1 gives an example of the way choices were presented. To give the professionals an intuition for the probabilities involved, we presented the options as pie charts with the sizes of the probabilities corresponding with the areas in the pie charts. Professionals could choose by clicking on their preferred option. They were then asked to confirm their choice. If they failed to do so, the same choice was presented again.

The final column of Table 1 shows the stimuli used. We selected substantial amounts of money to make the choices realistic. As a result, we could not play out the choices
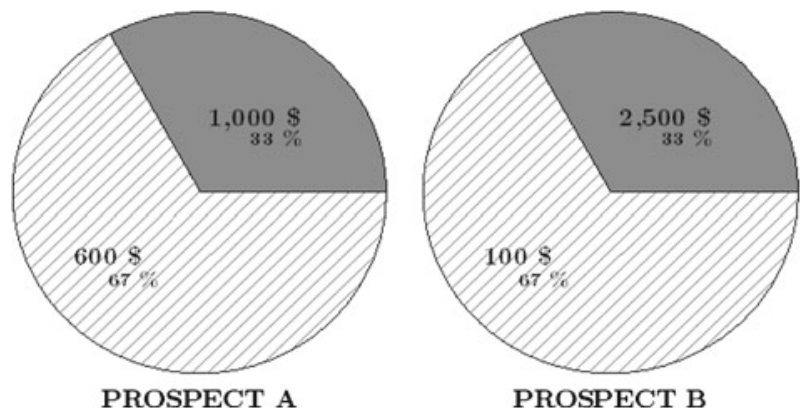

Fig. 1 Display of the experimental questions 
for real and all choices were hypothetical. We return to the issue of incentives in the discussion.

We elicited 11 data points for utility on the loss domain [ $-\$ 100000 ; 0], L_{0.015}$, $L_{0.031}, L_{0.062}, L_{0.093}, L_{0.125}, L_{0.25}, L_{0.375}, L_{0.5}, L_{0.625}, L_{0.75}$, and $L_{0.875}$, and eight data points on the gain domain $\left[0 ; G_{0.25}\right]: G_{0.015}, G_{0.031}, G_{0.062}, G_{0.093}, G_{0.125}$, $G_{0.156}, G_{0.187}$, and $G_{0.25}$. We collected more data for losses to facilitate the operationalization of Kahneman and Tversky's (1979) definition of loss aversion, and many data points around zero to be able to operationalize Köbberling and Wakker's (2005) definition of loss aversion.

\subsection{Tests of prospect theory}

Because our estimations depend crucially on the validity of prospect theory, we included several tests to verify whether the financial professionals behaved according to prospect theory. As a first test, at the end of the experiment we elicited the probability $p_{r}$ that made professionals indifferent to whether they received nothing or whether they received the prospect $\left(G_{r}, p_{r} ; L_{r}\right), r=0.031,0.0625,0.125$, and 0.25 . Remember that $G_{r}$ has utility $r$ and $L_{r}$ utility $-r$. By Eq. 2 and the results derived above, these indifferences imply that

$$
U(0)=0=w^{+}\left(p_{r}\right) r-w^{-}\left(1-p_{r}\right) r
$$

and, hence, that $w^{+}\left(p_{r}\right)=w^{-}\left(1-p_{r}\right)$. This equality holds for all four values of $r$. Because the probability weighting functions are increasing, the same probability $p_{r}$ should be obtained in all four questions if the professionals behaved according to prospect theory.

Our data also allowed for a second test to verify whether the professionals behaved according to prospect theory. In the first stage of the measurement, we elicited losses $\mathcal{L}_{0}, \mathcal{L}_{1}$, and $\mathcal{L}_{2}$ and gains $\mathcal{G}_{0}, \mathcal{G}_{1}$, and $\mathcal{G}_{2}$ such that $U\left(\mathcal{L}_{2}\right)-U\left(\mathcal{L}_{1}\right)=U\left(\mathcal{L}_{1}\right)-U\left(\mathcal{L}_{0}\right)$ and $U\left(\mathcal{G}_{2}\right)-U\left(\mathcal{G}_{1}\right)=U\left(\mathcal{G}_{1}\right)-U\left(\mathcal{G}_{0}\right)$ (see Table 1$)$. We only used these outcomes to determine the probabilities $p_{\ell}$ and $p_{g}$ for which $w^{-}\left(p_{\ell}\right)=w^{+}\left(p_{g}\right)=1 / 2$. They were not used in the actual measurement of utility. However, we could check whether the equalities between the utility differences were preserved in the measured utility function by using linear interpolation. If systematic deviations were to occur, then these would indicate that our professionals did not behave according to prospect theory.

\subsection{Methods of analysis}

For each professional, we analyzed the shape of utility on the gain and loss domain by looking at the evolution of the slope of utility. Both for gains and for losses, we determined the change in the slope of the utility function when moving away from the reference point. For gains, a decrease in the slope corresponded to concave utility, for losses it corresponded to convex utility. In total, we had 11 observations on the slope of utility on the loss domain and seven observations on the gain domain. To account for response error, we classified a professional as convex [concave] for losses if at least 7 
out of 11 observations were consistent with convexity [concavity]. A professional was concave [convex] for gains if at least four out of seven observations were consistent with concavity [convexity]. These classification rules are based on empirical research showing that choice reversal rates of up to 1/3 are common (Stott 2006).

In addition to the above nonparametric classification, we also analyzed the data assuming parametric specifications of utility. We will report the data based on the power family, which is commonly used in economics and finance. We also estimated exponential and expo-power specifications (Abdellaoui et al. 2007a), but these yielded similar conclusions and are, therefore, not reported separately. The power family is defined by $0.25\left(G_{r} / G_{0.25}\right)^{\alpha}$ for gains and by $-\left(L_{r} / 100000\right)^{\beta}$ for losses. For gains, $\alpha<1$ corresponds to concave utility, $\alpha>1$ to convex utility, and $\alpha=1$ to linear utility. For losses, $\beta<1$ corresponds to convex utility, $\beta>1$ to concave utility, and $\beta=1$ to linear utility.

To operationalize Kahneman and Tversky's (1979) definition of loss aversion, $-U(-x)>U(x)$ for all $x>0$, we computed the ratio $-\left(U\left(-G_{r}\right) / U\left(G_{r}\right)\right)$ for the eight values of $G_{r}$ that we elicited. This ratio can be interpreted as a loss aversion coefficient. The $-U\left(-G_{r}\right)$ were in general unknown and had to be determined through linear interpolation from the known values of $U\left(L_{r}\right)$. A professional was loss averse if at least six of the eight values of the loss aversion coefficient exceeded 1 , and gain seeking if at least six out of eight values were less than $1 . G_{0.25}$ exceeded $\$ 100,000$ for six subjects and we could not determine $-U\left(-G_{0.25}\right)$. For those subjects we computed the ratio $-\left(U\left(L_{r}\right) / U\left(-L_{r}\right)\right)$ for the 11 values of $L_{r}$ that were elicited and classified a subject as loss averse [gain seeking] if at least eight out of 11 ratios exceeded [were less than] 1. The reason for using a more stringent classification criterion for loss aversion than for utility curvature was that the sequential nature of our procedure made it more likely that if one response reflected loss aversion, the other responses would also reflect loss aversion. For example, if $G_{0.25}$ was much larger than $-L_{0.25}$, then the other $G_{r}$ were also likely to exceed the corresponding $-L_{r}$.

Köbberling and Wakker's (2005) definition of loss aversion implies that utility near the reference point is steeper for losses than for gains. To operationalize their definition, we took the loss and the gain closest to the reference point, $L_{0.015}$ and $G_{0.015}$, and computed the ratio of $U\left(L_{0.015}\right) / L_{0.015}$ over $U\left(G_{0.015}\right) / G_{0.015}$, i.e., we computed $G_{0.015} / L_{0.015}$. A value of $G_{0.015} / L_{0.015}$ exceeding 1 indicates loss aversion, a value less than 1 indicates gain seeking.

Significance of differences was tested both using parametric and nonparametric statistical tests. These typically gave the same results and therefore we will only report the parametric results unless otherwise stated.

\section{Results}

\subsection{Prospect theory}

The professionals satisfied the consistency tests and behaved according to prospect theory. In the first test, the median values of $p_{0.25}, p_{0.125}, p_{0.06}$, and $p_{0.03}$ were 0.71 , $0.66,0.71$, and 0.69 , respectively. As predicted by prospect theory, they were close and 
not significantly different (ANOVA with repeated measures, $p=0.17$ ). Our second test, the predicted equality between $U\left(\mathcal{L}_{0}\right)-U\left(\mathcal{L}_{1}\right)$ and $U\left(\mathcal{L}_{1}\right)-U\left(\mathcal{L}_{2}\right)$ and between $U\left(\mathcal{G}_{1}\right)-U\left(\mathcal{G}_{0}\right)$ and $U\left(\mathcal{G}_{2}\right)-U\left(\mathcal{G}_{1}\right)$, also supported the hypothesis that professionals behaved according to prospect theory. Neither $U\left(\mathcal{L}_{0}\right)-U\left(\mathcal{L}_{1}\right)$ and $U\left(\mathcal{L}_{1}\right)-U\left(\mathcal{L}_{2}\right)$ (paired $t$-test, $p=0.65$ ) nor $U\left(\mathcal{G}_{1}\right)-U\left(\mathcal{G}_{0}\right)$ and $U\left(\mathcal{G}_{2}\right)-U\left(\mathcal{G}_{1}\right)$ (paired $t$-test, $p=0.06)$ were significantly different.

The median probabilities $p_{g}$ and $p_{\ell}$ for which $w^{+}\left(p_{g}\right)=w^{-}\left(p_{\ell}\right)=1 / 2$ were equal to 0.64 and 0.47 . The probability $p_{g}$ was significantly greater than 0.50 ( $t$-test, $p=0.01)$, the value of $p_{g}$ predicted by expected utility; $p_{\ell}$ did not differ significantly from 0.50 ( $t$-test, $p=0.86$ ). These data suggest significant underweighting of probabilities for gains around $1 / 2$ and no probability weighting for losses around 1/2. Considerable variation existed at the individual level. The value of $p_{g}$ varied between 0.19 and 0.98 with an interquartile range of $[0.33,0.79]$. The value of $p_{\ell}$ varied between 0.06 and 0.96 with an interquartile range of [0.34, 0.63]. As we used $p_{g}$ and $p_{\ell}$ in the elicitation of utility, these values imply that for the large majority of professionals no extreme probabilities, i.e., probabilities near 0 or 1 , were used in the choice questions. Probability weighting for gains was similar to that observed in previous studies using student samples (e.g., Gonzalez and Wu 1999; Abdellaoui 2000; Bleichrodt and Pinto 2000), but the pattern was different for losses.

\subsection{Utility}

\subsubsection{Aggregate analysis}

In agreement with the predictions of prospect theory, we observed risk aversion for gains and risk seeking for losses. ${ }^{8}$ For gains, there were 232 risk averse answers, 89 risk seeking answers, and 1 risk neutral answer. ${ }^{9}$ The proportion of risk averse answers was significantly higher than the proportion of risk neutral and risk seeking answers $(t$-test, $p<0.001) .{ }^{10}$ For losses, there were 295 risk seeking answers, 207 risk averse answers, and 4 risk neutral answers and the proportion of risk seeking answers was significantly higher than the proportion of risk averse and risk neutral answers $(p=0.040)$. The proportion of risk averse answers differed significantly between gains and losses confirming prospect theory's assumption that risk attitudes are sign-dependent $(p<0.001)$.

Figure 2 shows the utility function for the median data. The interrupted line shows the case of linear utility. As predicted by prospect theory, utility was concave for gains

\footnotetext{
8 The median values for $L_{0.015}, L_{0.031}, L_{0.062}, L_{0.093}, L_{0.125}, L_{0.25}, L_{0.375}, L_{0.5}, L_{0.625}, L_{0.75}$, and $L_{0.875}$ were $-1330,-2095,-4850,-7860,-10450,-24000,-33250,-46350,-58200,-70050$, and -82300 , respectively. The median values of $G_{0.015}, G_{0.031}, G_{0.062}, G_{0.093}, G_{0.125}, G_{0.156}, G_{0.187}$, and $G_{0.25}$ were $870,1875,4015,6015,10800,13300,17950$, and 32350 , respectively.

9 A risk averse [seeking, neutral] answer is defined as a response smaller than [greater than, equal to] the expected value of the prospect.

10 To account for the fact that individual responses are likely to be correlated and cannot be treated as independent, we estimated a random effects probit model using the pglm package in $R$. The reported $p$-values are based on the $t$-tests corresponding to these estimates.
} 


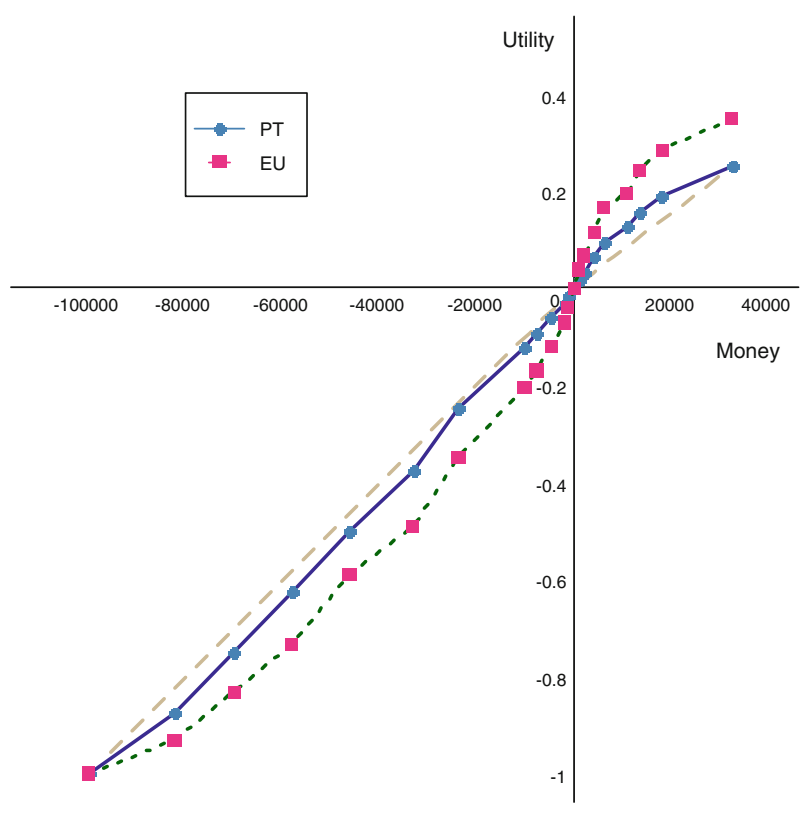

Fig. 2 The utility function based on the median data

and convex for losses. Our data were not consistent with reflection, however. The degree of curvature was more pronounced for gains than for losses. The utility for losses was close to linear. Consistent with the deviation from reflection, the power coefficients (the coefficients of relative risk aversion) differed significantly across two domains. They were 0.93 for losses and 0.71 for gains (paired $t$-test, $p<0.01$ ).

Figure 2 also shows the utility function under expected utility, i.e., when probability weighting is assumed to be linear. The figure shows that our financial professionals clearly deviated from expected utility. Wrongly assuming expected utility leads to an overstatement of the curvature of utility: utility is too concave for gains and too convex for losses. This overstatement of curvature is also reflected in the estimated power coefficients. Under expected utility, the power coefficients were 0.57 for gains and 0.70 for losses. Both coefficients differed significantly from those estimated under prospect theory (paired $t$-test, $p<0.001$ in both comparisons).

\subsubsection{Individual analysis}

The pattern of concave utility for gains and convex utility for losses was also observed at the individual level. Table 2 presents the results of the non-parametric classification. Twenty-seven professionals had concave utility for gains and convex utility for losses. Only four professionals had the pattern traditionally assumed in economics and finance of utility everywhere concave.

Figure 3 shows the distribution of the individual power coefficients. Concave utility was clearly the most common shape for gains. There were few subjects with convex utility for gains. Slight convexity was the most common shape for losses, but 
Table 2 Non-parametric classification professionals based on the shape of their utility function

\begin{tabular}{lllll}
\hline Gains & Losses & & & \\
\cline { 2 - 5 } & Concave & Convex & Mixed & Total \\
\hline Concave & 4 & 27 & 11 & 42 \\
Convex & 0 & 1 & 3 & 4 \\
Total & 4 & 28 & 14 & 46 \\
\hline
\end{tabular}

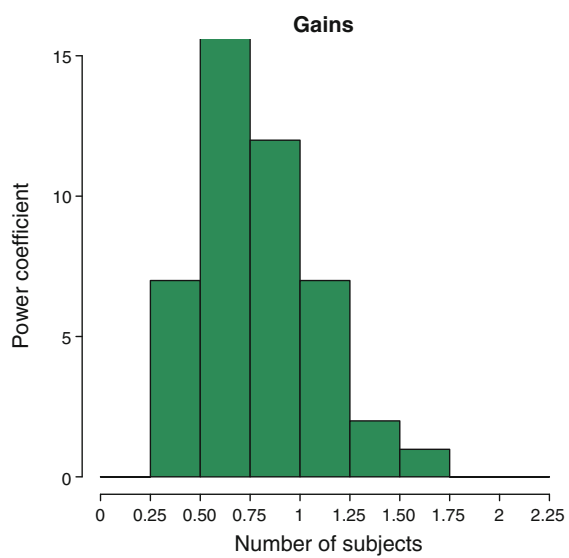

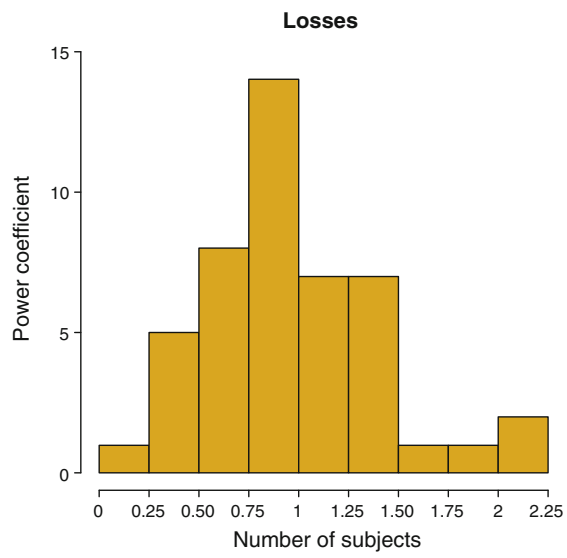

Fig. 3 Distributions of the individual power coefficients for gains and for losses

a substantial fraction of subjects had concave utility for losses. We found considerable variation at the individual level, in particular for losses. The power coefficients varied between 0.36 and 1.54 with an interquartile range of $[0.62,0.98]$ for gains and between 0 and 2.18 with an interquartile range of $[0.67,1.20]$ for losses.

Reflection was also violated at the individual level. Under reflection, we would expect a positive correlation between the individual power coefficient for gains and the individual power coefficient for losses. However, this correlation was significantly negative: $\rho=-0.36(p=0.016)$.

\subsection{Loss aversion}

Figure 4 shows the relationship between the medians of gains and losses that have the same absolute utility. We could compare six pairs $\left(G_{r}, L_{r}\right)$. According to Kahneman and Tversky's (1979) definition, that loss aversion holds if for all $x>0, U(x)<$ $-U(-x)$, we should observe that for all $r, G_{r}>L_{r}$. That is, we should observe that all points lie below the diagonal. This was clearly not the case. $G_{r}$ and $L_{r}$ were approximately equal for smaller money amounts. The data were only consistent with Kahneman and Tversky (1979) definition of loss aversion for larger money amounts. 
Fig. 4 The relationship between median gains and median losses with the same absolute utility

Table 3 Individual results for loss aversion

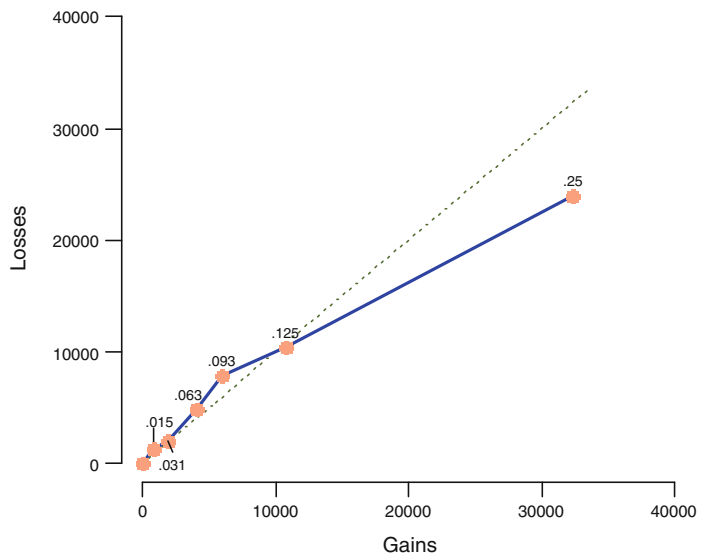

\begin{tabular}{llll}
\hline Definition & Loss averse & $\begin{array}{l}\text { Gain } \\
\text { seeking }\end{array}$ & $\begin{array}{l}\text { Median } \\
\text { coefficient }\end{array}$ \\
\hline Kahneman and Tversky (1979) & 18 & 13 & 1.31 \\
Köbberling and Wakker (2005) & 21 & 22 & 1.00 \\
\hline
\end{tabular}

The data were not consistent with Köbberling and Wakker's (2005) definition of loss aversion either. Close to the reference point, utility was approximately linear and, hence, loss aversion would imply that there we should find $G_{r}>L_{r}$. The data provided no evidence for this prediction.

Table 3 presents the classification of the financial professionals based on the definitions by Kahneman and Tversky (1979) and by Köbberling and Wakker (2005). ${ }^{11}$ Perhaps surprisingly, the data did not show strong support for loss aversion. The proportions of loss averse and gain seeking professionals did not differ significantly for both definitions (binomial test, $p>0.10$ in both comparisons). The median loss aversion coefficient under Kahneman and Tversky's (1979) definition indicated loss aversion. It differed significantly from $1(p<0.001)$ and was similar to the values obtained by Kliger and Levy (2009) and Gurevich et al. (2009). According to Köbberling and Wakker's (2005) definition, the median loss aversion coefficient was equal to 1 , corresponding to loss neutrality. The correlation between the values obtained based on Kahneman and Tversky's (1979) definition and those based on Köbberling and Wakker's (2005) definition was low (0.14) and not significantly different from 0.

Figure 5 displays the distribution of the individual loss aversion coefficients for both Kahneman and Tversky's (1979) and Köbberling and Wakker's (2005) definition of loss aversion. Once again, we observed considerable heterogeneity at the individual level. The interquartile ranges were $[0.79,2.26]$ for Kahneman and Tversky's (1979)

11 We also analyzed the data under the definition of Wakker and Tversky (1993) that at every loss, utility should be steeper than at the corresponding gain. The results were similar, except that the number of subjects who could not be classified was larger. 

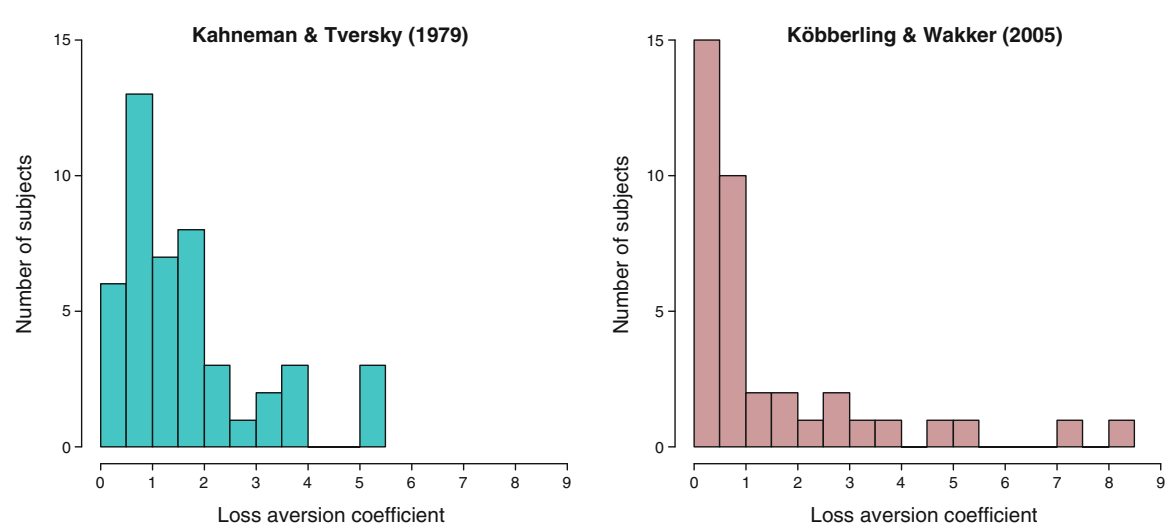

Fig. 5 Distributions of individual loss aversion coefficients

Table 4 Median loss aversion coefficients by country and sex

\begin{tabular}{lllllll}
\hline & \multicolumn{2}{l}{ Country } & & \multicolumn{2}{l}{ Sex } \\
\cline { 2 - 3 } \cline { 6 - 7 } & US & Lebanon & & Female & Male \\
\hline Kahneman and Tversky (1979) & 1.53 & 1.08 & & 1.32 & 1.30 \\
Köbberling and Wakker (2005) & 1.01 & 0.67 & & 0.69 & 1.00 \\
\hline
\end{tabular}

definition and [0.24, 2.93] for Köbberling and Wakker's (2005) definition. Depending on the definition used, the interquartile ranges show that a quarter of the professionals weighed gains 1.25 to 4 times as heavy as losses. This contributed to strong risk seeking behavior. Some professionals hardly paid any attention to losses and seized any opportunity for a gain regardless of the losses involved.

\subsection{Demographic characteristics}

Table 4 shows that loss aversion was higher for the US-based professionals compared to the Lebanon-based professionals. However, the differences were not significant (paired $t$-test, $p>0.10$ in both comparisons). The lack of significance may have been due to the relatively small sample sizes. Loss aversion between females and males was similar, but it should be kept in mind that we only had nine female subjects in our sample. Older subjects tended to be more loss averse. The correlation between age and loss aversion was positive (0.22) but insignificant ( $t$-test, $p=0.15$ ) based on Kahneman and Tversky's (1979) definition, whereas it was positive (0.48) and significant ( $t$-test, $p=0.001$ ) based on Köbberling and Wakker's (2005) definition.

\subsection{Comparison with ABP}

Table 5 compares our main results with those of ABP (2007b). When comparing these results it should be borne in mind that the studies differ in several respects, but are sufficiently close in terms of methodology and stimuli used to provide some insight 
Table 5 Comparison with ABP

\begin{tabular}{llll}
\hline & ABP & This study & Significance \\
\hline Power gains & 0.72 & 0.73 & n.s. \\
Power losses & 0.73 & 0.86 & $p=0.031$ \\
$\begin{array}{l}\text { Loss aversion } \\
\quad(\text { Kahneman and Tversky 1979) }\end{array}$ & 1.69 & 1.31 & $p=0.049$ \\
$\begin{array}{l}\text { Loss aversion } \\
\quad \text { Köbberling and Wakker 2005) }\end{array}$ & 2.54 & 1.00 & $p=0.044$ \\
\hline
\end{tabular}

A: Utility based on the median data

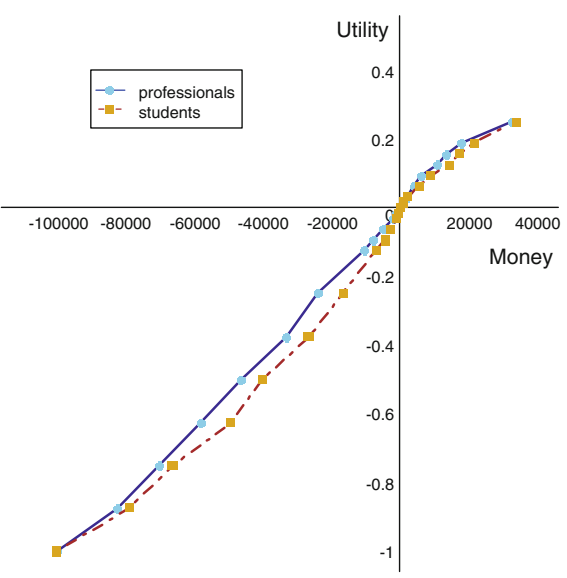

B: The relationship between median gains and median losses with the same absolute utility

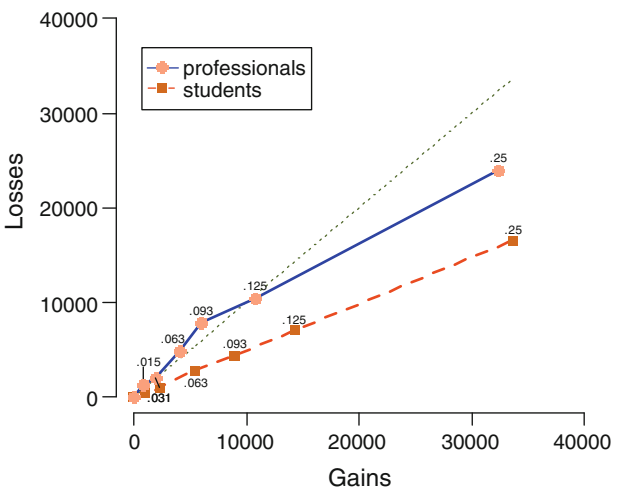

Fig. 6 A comparison between our sample of professionals with the student sample of ABP (2007b)

into the question whether the preferences of our financial professionals differed from those observed using a student sample. The table shows that this was clearly the case. Utility for gains was comparable, but the financial professionals had less convex utility for losses (contributing to less risk seeking behavior for losses), and they were less loss averse (contributing to more risk seeking in mixed prospects) according to both definitions than the student sample in ABP (2007b).

The difference between our sample of financial professionals and the student sample of ABP (2007b) is further illustrated in Figs. 6A, B. Figure 6A shows the elicited utility functions based on the median data. The figure shows that utility is almost identical for gains in the two samples, but more convex for losses for ABP's students than for our professionals. The figure shows that the kink at 0 is larger for the students, entailing higher loss aversion in the student sample according to Köbberling and Wakker's (2005) definition. Higher loss aversion for the students is also evident in Fig. 6B, showing the relationship between median gains and median losses with the same absolute utility. The interrupted line, showing the student data, lies everywhere below the professionals' uninterrupted line implying more loss aversion according to Kahneman and Tversky's (1979) definition. 


\section{Discussion}

Prospect theory has become an important tool to explain deviations from the classical paradigm of rational agents. However, the available support for prospect theory comes almost exclusively from student samples and there is only scant evidence on the preferences of professional actors in the market. This article addresses this gap in the literature and presents quantitative evidence whether financial professionals behave according to prospect theory and whether the prospect theory parameters commonly observed in the lab and assumed in the literature reflect their behavior.

Our results support prospect theory. The financial professionals in our sample behaved according to prospect theory and violated expected utility. They were risk averse for gains and risk seeking for losses and their utility was concave for gains and convex for losses both at the individual and at the aggregate level. Utility was more curved on the gain domain than on the loss domain. The median professional was loss averse, but less so than what is commonly observed in the lab and than what is assumed in behavioral models of financial decision-making. This finding is consistent with Kliger and Levy (2009) and Gurevich et al. (2009) despite the difference in data and experimental methods used. One should keep in mind though that our experiment was different from the typical lab experiment in some respects. In particular, to make the choices realistic and to mimic their behavior as professionals, we told our subjects that they were handling the company's money, whereas subjects in the lab typically make risky choices involving their own money.

Most models that apply prospect theory in finance rely heavily on loss aversion. They assume a loss aversion coefficient of at least 2, implying that losses weigh at least twice as heavy as gains. This strong degree of loss aversion is the main driving force behind the explanation of several anomalous empirical findings. Our data did not support such strong loss aversion. The assumptions used in behavioral finance do not seem to capture the behavior of financial professionals and our data suggest that using Tversky and Kahneman's (1992) parameters requires reconsideration when wishing to model the behavior of financial professionals. Loss aversion plays a role in explaining financial decisions, but it may not be as important as typically assumed.

It should be emphasized that our observation of lower loss aversion does not necessarily imply that the assumptions used in behavioral finance are incorrect. Rather we interpret our findings as providing a more complete picture of what drives financial market players. College students may be similar to private investors in that they tend to make one-shot decisions and are less frequently exposed to feedback. Even for financial professionals, our findings do not necessarily challenge models in behavioral finance. For example, Benartzi and Thaler (1995) explain the equity premium puzzle through a combination of loss aversion and frequent evaluation of portfolios. Based on Tversky and Kahneman's (1992) estimate of the coefficient of loss aversion of 2.25, they conclude that investors use an evaluation period of approximately one year, a period they call "plausible". If loss aversion is lower, then the evaluation period must be shorter to explain the equity premium puzzle. A shorter evaluation period may not be implausible for financial professionals like the subjects in this study. In fact, some of our professionals mentioned that they evaluate their portfolio every 6 weeks. 
We used hypothetical choices throughout the experiment. We could not use real incentives because the stakes involved had to be large enough to make the decisions realistic for our financial professionals. We do not believe that using hypothetical choices affected our conclusions. First, most studies that address the issue of hypothetical versus real incentives have found that the obtained patterns of behavior were similar for the kind of task performed in this experiment (Beattie and Loomes 1997; Camerer and Hogarth 1999; Bardsley et al. 2010) although some studies have observed that real incentives can matter (Hertwig and Ortmann 2001). Second, time was very valuable for our subjects, being highly paid financial professionals. The fact that they were willing to respond to a variety of questions indicates that they took the tasks seriously. Our computer program made it possible to show the elicited utility function and its underlying psychology immediately after the interview was completed. Most professionals were keen to learn about this and asked for a summary of the results to be sent to them. When we explained the intuition of prospect theory after the interview was completed, they agreed that prospect theory reflected the major aspects of their decision-making process.

As mentioned before, we used sizeable amounts of money to make the choices realistic. However, perhaps the stakes were too small for our financial professionals who are used to handling large amounts of money. On the other hand, most of our subjects worked for commercial banks and typically handled transactions up to $\$ 100,000$. We can only speculate about the effect of high payoffs. There is some empirical evidence suggesting that raising payoffs produces more risk aversion (Binswanger 1980; Holt and Laury 2002). Under prospect theory, such risk aversion can be captured by more concave utility, by less elevated probability weighting, or by more pronounced loss aversion.

A critical element of prospect theory is the location of the reference point. Throughout the experiment, we assumed that the reference point was 0 , the case of no gain and no loss. Our financial professionals may well have used a different reference point, e.g., some target level of return. In defense of our assumption about the reference point, we observed the usual risk aversion for gains and risk seeking for losses and the shape of utility was consistent with the predictions of prospect theory.

Let us finally consider the question why we only observed limited evidence of loss aversion. One explanation is that financial professionals have learnt to deal with losses. Consequently, their assessment of losses is different compared to students, for instance. A second explanation may be that the compensation package of financial professionals often depends on achieved gains. This may induce more gain seeking, or equivalently, less loss aversion. Typically, fund managers receive a management fee of between 1 and $2 \%$ of the assets under management and an incentive fee of 20 and $25 \%$ of the profits of the fund. In addition, they receive a bonus when they beat the corresponding index. Knowing which of these two explanations is true is important for applications of prospect theory. The first explanation suggests that loss aversion could be reduced through experience and, hence, would be less important in (frequent) real-life decisions than lab data suggest. In the second explanation, experience plays no role and does not affect loss aversion.

It should be kept in mind when interpreting our results that our sample size was necessarily limited, because it was difficult to recruit financial professionals. 
Nevertheless, our findings caution against the use of estimates from student samples in modeling the decisions of financial professionals. We hope that future studies will keep this in mind and that our study will contribute to a more accurate modeling of financial decisions.

Acknowledgments Mohammed Abdellaoui's research was supported by a grant from Agence Nationale de la Recherche (Risk Attitude Project), France. Han Bleichrodt's research was made possible by a grant from the Netherlands Organization for Scientific Research (NWO). Nick Barberis, Jan Boone, Olivier l'Haridon, Tobias Klein, Charles Noussair, Jan Potters, Martijn van den Assem, and Peter Wakker gave helpful comments.

Open Access This article is distributed under the terms of the Creative Commons Attribution Noncommercial License which permits any noncommercial use, distribution, and reproduction in any medium, provided the original author(s) and source are credited.

\section{References}

Abdellaoui, M. (2000). Parameter-free elicitation of utility and probability weighting functions. Management Science, 46, 1497-1512.

Abdellaoui, M., Barrios, C., \& Wakker, P. P. (2007a). Reconciling introspective utility with revealed preference: Experimental arguments based on prospect theory. Journal of Econometrics, 138, 356378.

Abdellaoui, M., Bleichrodt, H., \& Paraschiv, C. (2007b). Measuring loss aversion under prospect theory: A parameter-free approach. Management Science, 53, 1659-1674.

Barberis, N., \& Huang, M. (2001). Mental accounting, loss aversion, and individual stock returns. Journal of Finance, 56, 1247-1292.

Barberis, N., Huang, M., \& Santos, T. (2001). Prospect theory and asset prices. Quarterly Journal of Economics, 66, 1-53.

Barberis, N., \& Xiong, W. (2009). What drives the disposition effect? An analysis of a long-standing preference-based explanation. Journal of Finance, 64, 751-784.

Bardsley, N., Cubitt, R., Loomes, G., Moffatt, P., Starmer, C., \& Sugden, R. (2010). Experimental economics: Rethinking the rules. Princeton: Princeton University Press.

Beattie, J., \& Loomes, G. (1997). The impact of incentives upon risky choice experiments. Journal of Risk and Uncertainty, 14, 155-168.

Benartzi, S., \& Thaler, R. H. (1995). Myopic loss aversion and the equity premium puzzle. Quarterly Journal of Economics, 110, 73-92.

Binswanger, H. P. (1980). Attitude toward risk: Experimental measurement in rural India. American Journal of Agricultural Economics, 62, 395-407.

Bleichrodt, H., \& Pinto, J. L. (2000). A parameter-free elicitation of the probability weighting function in medical decision analysis. Management Science, 46, 1485-1496.

Booij, A. S., \& van de Kuilen, G. (2009). A parameter-free analysis of the utility of money for the general population under prospect theory. Journal of Economic Psychology, 30, 651-666.

Bostic, R., Herrnstein, R. J., \& Luce, R. D. (1990). The effect on the preference reversal of using choice indifferences. Journal of Economic Behavior and Organization, 13, 193-212.

Camerer, C. F., Babcock, L., Loewenstein, G. F., \& Thaler, R. H. (1997). Labor supply of New York City cabdrivers: One day at a time. Quarterly Journal of Economics, 112, 407-442.

Camerer, C. F., \& Hogarth, R. M. (1999). The effects of financial incentives in experiments: A review and capital-labor-production framework. Journal of Risk and Uncertainty, 19, 7-42.

Coval, J. D., \& Shumway, T. (2005). Do behavioral biases affect prices?. Journal of Finance, 60, 1-34.

Gneezy, U., Kapteyn, A., \& Potters, J. (2003). Evaluation periods and asset prices in a market experiment. Journal of Finance, 58, 821-837.

Gneezy, U., \& Potters, J. (1997). An experiment on risk taking and evaluation periods. Quarterly Journal of Economics, 102, 631-645.

Gonzalez, R., \& Wu, G. (1999). On the form of the probability weighting function. Cognitive Psychology, 38, 129-166. 
Gurevich, G., Kliger, D., \& Levy, O. (2009). Decision-making under uncertainty: A field study of cumulative prospect theory. Journal of Banking and Finance, 33, 1221-1229.

Haigh, M., \& List, J. A. (2005). Do professional traders exhibit myopic loss aversion? An experimental analysis. Journal of Finance, 60, 523-534.

Hertwig, R., \& Ortmann, A. (2001). Experimental practices in economics: A methodological challenge for psychologists? Behavioral and Brain Sciences, 24, 383-451.

Holt, C. A., \& Laury, S. K. (2002). Risk aversion and incentive effects. American Economic Review, 92, 1644-1655.

Kahneman, D., \& Tversky, A. (1979). Prospect theory: An analysis of decision under risk. Econometrica, 47, 263-291.

Kliger, D., \& Levy, O. (2009). Theories of choice under risk: Insights from financial markets. Journal of Economic Behavior \& Organization, 71, 330-346.

Köbberling, V., \& Wakker, P. P. (2005). An index of loss aversion. Journal of Economic Theory, 122, $119-131$.

List, J. A. (2003). Does market experience eliminate market anomalies? Quarterly Journal of Economics, 118, 41-71.

Myagkov, M., \& Plott, C. R. (1997). Exchange economies and loss exposure: Experiments exploring prospect theory and competitive equilibria in market environments. American Economic Review, 87, 801-828.

Rabin, M. (2000). Risk aversion and expected-utility theory: A calibration theorem. Econometrica, 68, 1281-1292.

Stott, H. P. (2006). Cumulative prospect theory's functional menagerie. Journal of Risk and Uncertainty, 32, 101-130.

Thaler, R. H., Tversky, A., Kahneman, D., \& Schwartz, A. (1997). The effect of myopia and loss aversion on risk taking: An experimental test. Quarterly Journal of Economics, 102, 647-661.

Tom, S. M., Fox, C. R., Trepel, C., \& Poldrack, R. A. (2007). The neural basis of loss aversion in decision-making under risk. Science, 315, 515-518.

Tversky, A., \& Kahneman, D. (1992). Advances in prospect theory: Cumulative representation of uncertainty. Journal of Risk and Uncertainty, 5, 297-323.

van de Kuilen, G., \& Wakker, P. P. (2006). Learning in the Allais paradox. Journal of Risk and Uncertainty, 33, 155-164.

Wakker, P. P., \& Tversky, A. (1993). An axiomatization of cumulative prospect theory. Journal of Risk and Uncertainty, 7, 147-176. 